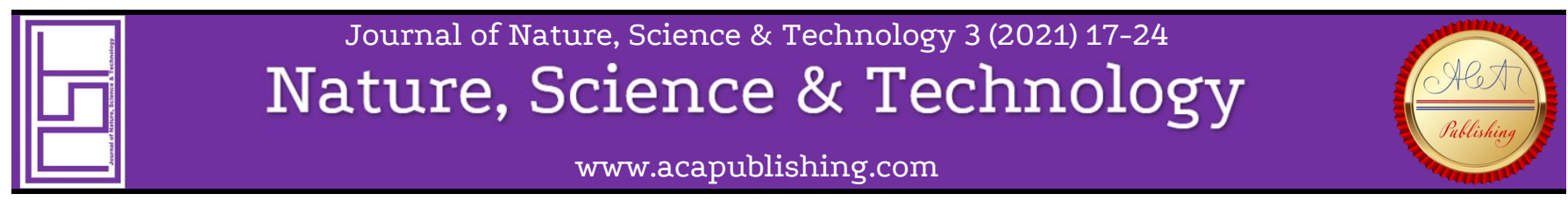

Research Article

\title{
Phenolic Reaction Products from The Thermal Degradation of Catha edulis
}

\author{
Micah O. Omare, ${ }^{1,4}$, Joshua K. Kibet*2, Jackson K. Cherutoi ${ }^{1,4}$, Fredick O. Kengara ${ }^{3,4}$. \\ ${ }^{1}$ School of Science and Aerospace studies, department of Chemistry and Biochemistry, Moi University, P.O Box 3900 -30100, \\ Eldoret, Kenya \\ 2 Department of Chemistry, Egerton University, P.O Box 536-20115, Egerton, Kenya \\ ${ }^{3}$ Department of Chemistry, Bomet University College, Bomet, Kenya \\ ${ }^{4}$ Africa Center of Excellence II in Phytochemicals, Textiles and Renewable Energy (ACE II PTRE), Moi University, Uasin Gishu \\ County, P.O. Box 3900-30100, Eldoret, Kenya
}

\section{Keywords}

Khat pyrolysis,

Penolic compounds,

Khat smoke,

Geometry optimization

Molecular geometries

\begin{abstract}
Herein, we report phenolic reaction products from the thermolysis of khat that is important in understanding the smoking of khat under conditions that are representative of cigarette smoking. Phenolic compounds occur naturally and are precursors for grave environmental health problems such as cancer and cell injury. This study investigates the phenolic compounds generated from the thermal degradation of Catha edulis, computes the global energies and entropies of selected phenolic compounds and their derivatives, and performs their geometry optimization using Gaussian '09 computational code. In addition, we report on the elemental speciation of thermal char from khat pyrolysis. The thermal degradation of khat was conducted in an inert nitrogen environment at 1 atmosphere at a contact time of 2s using a quartz tubular reactor. The pyrolysis effluent was characterized using a Gaschromatograph coupled to a mass spectrometer. The GC-MS results indicated that khat pyrolysis yielded a significant number of phenolic compounds such as phenol, $p$-cresol, catechol, hydroquinone and substituted methoxy phenols. The maximum release of these compounds occured between 400 and $550{ }^{\circ} \mathrm{C}$. Hydroquinone gave the highest yield of $21.32 \%$ in the entire pyrolysis temperature while $p$-cresol gave a yield of $2.54 \%$ in the same temperature range. Phenolic compounds exhibited endothermicity with increase in temperature. Because of the potent nature of khat cigarette, it is necessary for government authorities, policy makers and medical practioners to mount campaigns against khat smoking.
\end{abstract}

\section{Introduction}

The chemistry of phenols in general is an interesting subject because of the remarkable toxic and health concerns associated with them. Phenols especially polyphenols are considered very important radical scavenging groups and may be used to reduce the effects of oxidative stress and related biological diseases. The natural environment comprises of a variety of phenolic compounds which occur naturally (pyrocatechol, guaiacol, pyrogallol, eugenol and, thymol) and some as a result of continuous human activities such as industrial and agricultural activities which pose grave environmental risks [1]. Nonetheless, the phenolic groups such as phenol, hydroquinone, cresols, and methoxy substituted phenols and their associated free radicals are of serious health concern. This observation is compounded further during cigarette smoking or khat smoking. In the emerging drug abuse techiques of modern times, dried khat leaves are rolled into cigarette sticks or placed at the end of a pipe prior to smoking. The result is the delivery of toxic phenols and environmentally free radicals into the biological system where they are likely to cause injury on important body organs. Accordingly, Kibet et al. (2015) reported some of the molecular phenolic compounds such as $p$-cresol, $o$-cresol, $m$-cresol, catechol, hydroquinone, and methoxy-substituted phenols to cause a greater environmental pollution and health effects and higher reactivity index with biological systems [2]. This work investigates the distribution of phenolic reaction products from the thermal degradation of khat leaves under conditions that are representative of cigarette smoking.
Generally, the structural design of phenolic compounds incorporate one or more hydroxyl groups (-OH) linked to the aromatic system such as phenyl. Some examples of phenolic compounds and their structures are shown in Fig 1. Phenols are known to attack the enzymes of the liver, lungs, kidneys and initiate complications associated with cardiovascular infections and the nervous system in humans [3]. Despite the extensive amounts of research conducted on phenolic compounds, limitation still exists in identifying their possible sources in the environment. Therefore, it is fundamental to assess the possible generation of phenols from the thermal degradation of a variety of biomass materials such as khat, a class $C$ drug substance whose use and possession has excited serious debate among scholars and medical practioners as an emerging illegal drug $[4,5]$.

Even though khat is criminalized for possession by some western countries, its legalization for cultivation and use in East African has made it possible for its sale and smuggling into the world markets such as the United States of America (USA) and the United Kingdom (UK) that are currently experiencing increase in demand for its consumption by a wider demographic of individuals [6, 7].Traditionally, khat chewing involves reserving raw but fresh leaves, twigs or shoots (Fig 2a) in the cheeks, recurrent munching in order to emancipate the dynamic drug components in a sap which gets dissolved in saliva to release the main psychoactive khat alkaloids, cathinone (Fig $3 \mathrm{a}$ ) and cathine (Fig $3 b$ ) which are the main chemicals for khat addiction [8]. Consequently, some communities have resorted 
to the use of khat in form of cigarettes where dried khat leaves (Fig 2 b), are packaged into cigars and ultimately smoked [9].<smiles>Oc1ccccc1</smiles>
phenol<smiles>Oc1cc(O)c2c(O)c1O[Ge]2Cl</smiles>

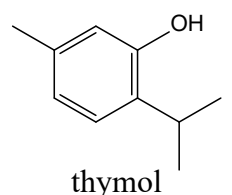
thymol<smiles>Oc1ccccc1COc1ccccc1</smiles><smiles></smiles><smiles>Oc1cccc2ccccc12</smiles><smiles>N[C@@H](Cc1ccc(O)cc1)C(=O)O</smiles><smiles>Oc1ccccc1O</smiles>
pyrocatechol<smiles>O=[N+]([O-])c1cc([N+](=O)[O-])c(O)c([N+](=O)[O-])c1</smiles><smiles>Oc1cccc(O)c1O</smiles>
pyrogallol<smiles>O=C(O[Ga])c1ccc(O)cc1</smiles><smiles>Oc1ccc(O)c(O)c1</smiles>

hydroxyhydroquinone<smiles>Oc1ccccc1Cl</smiles>

o-chlorophenol<smiles>O=C(O)c1cccc([GaH])c1OC(Cl)Cl</smiles><smiles>CC(N)C(=O)c1ccccc1</smiles>

a<smiles>C[C@@H](N)[C@H](O)c1ccccc1</smiles>

b
Fig 3: Khat alkaloids (a) cathinone (b) cathine

The possible generation of toxic particulates including intermediate radicals and molecular products such as formaldehydes and acetaldehydes throughout the pyrolysis temperatures have been reported to be the major agents that contribute to biomass carcinogenicity, cytotoxicity and genotoxicity [17]. For instance, Lin et al. (2008) analyzed mainstream tobacco smoke and reported the occurrence of acetaldehyde which is known to be addictive and carcinogenic [18]. Moreover, polycyclic aromatic hydrocarbons (PAHs) such as benzo[a]pyrene that are well established as environmentally carcinogenic have been intensely researched and identified to be predecessors of benzene, 1,3-butadiene and isoprene which have been identified to be present in high concentrations in tobacco smoke [19, 20]. In addition, cellular damage in a number of smokers has been linked to the production of phenolic compounds and their corresponding free radicals such as phenoxy free radical that are environmentally persistent because of their long-life times [21]. Of interest, the production of phenolic compounds from raw khat both before, during and after mastication has received little attention in research. Besides, the increase in the use of khat in form of cigarettes and the chemical analysis of the phenolic compounds emitted during khat smoking has not been well documented in literature. For this reason, the toxicity of khat cigarette smoke and the possibility of the evolution of phenolic compounds as potential carcinogens will be reported in detail. In addition, elemental speciation of char from khat pyrolysis will be analysed. The application of quantum chemistry has been identified as a useful tool in the generation and calculation of thermodynamic data that can be employed in making accurate reaction predictions for molecules whose experimental data are unknown [22]. The use of density functional theory (DFT) has been successfully utilized under the Gaussian computational package in describing the structural and consequently the obtained data were applied in describing the molecular system [23]. Accordingly, this work wills compute the global energies and entropies of phenol and its derivatives from khat biomass pyrolysis and perform geometry optimization using Gaussian'09 computational code. electronic properties of a series of molecules and atoms and

\section{Experimental procedure 2.1 Sample collection and preparation}

Fresh khat shoots were collected from khat farms in Maua municipality, Igembe South Sub-County, Meru county - Kenya. The samples were packaged in polythene carrier bags and transported to the laboratory where they were thoroughly sorted to remove any foreign matter, cleaned with distilled water followed by rinsing with a mixture of de-ionized and distilled water, dried in an electric oven at temperatures of $45{ }^{\circ} \mathrm{C}$ for 96 hours to remove moisture and then used without further treatment. The dried leaves were ground and sieved using a 45 micron mesh.

\subsection{Materials}

All chemicals used for this study were of analytical grade. The reagents; $p$-cresol, o-cresol, $m$-cresol, catechol, hydroquinone, and methoxy-substituted phenols had a purity $\geq 99.99 \%$. The reagents were purchased from Sigma-Aldrich, South Africa and used without further modification.
Fig 2: (a) Fresh khat twigs, leaves and shoot [10] (b) dried khat twigs and leaves 


\subsection{Reactor design and assembly}

The reactor was designed and assembled as illustrated in Fig 4. It comprised of a set of units; the reactor compartment which houses the electrical heater and the reactor; temperature control unit which regulates the pyrolysis temperature within a temperature gradient of $50{ }^{\circ} \mathrm{C} / \mathrm{min}$. A quartz tubular reactor of volume $49.96 \mathrm{~mL}$ was used for the pyrolysis of dried khat biomass. A residence time of $2 \mathrm{~s}$ was selected for all temperature runs. The flow rates of the pyrolysis gas through the reactor based on a residence time of 2 seconds were calculated using equation 1.

$$
F_{0}=\left(\frac{\pi r^{2} L}{t_{0}}\right)\left(\frac{T_{1}}{T_{0}}\right) x\left[1+\frac{P_{d}}{P_{0}}\right] .
$$

where $t_{0}$ represents the resident time and $F_{0}$ the flow rate of pyrolysis gas, controlled by a digital mass flow meter that has the capacity to deliver up to $6000 \mathrm{~mL} / \mathrm{min}$ of gas into the reactor system. To refers to the reactor temperature before pyrolysis, $\mathrm{T}_{1}$ the reactor temperature after pyrolysis, $L$ is the reactor length and $r$ the internal radius of the reactor. $\mathrm{P}_{\mathrm{d}}$ is the pressure difference between the inlet pressure and the pressure inside the reactor while $P_{0}$ represents the internal reactor pressure before pyrolysis. Accordingly, the flow rates for the temperatures of 250,500 and $700{ }^{\circ} \mathrm{C}$ were $2630.33 \mathrm{~mL} / \mathrm{min}, 3887.66$ $\mathrm{mL} / \mathrm{min}$ and $4893.52 \mathrm{~mL} / \mathrm{min}$, respectively.

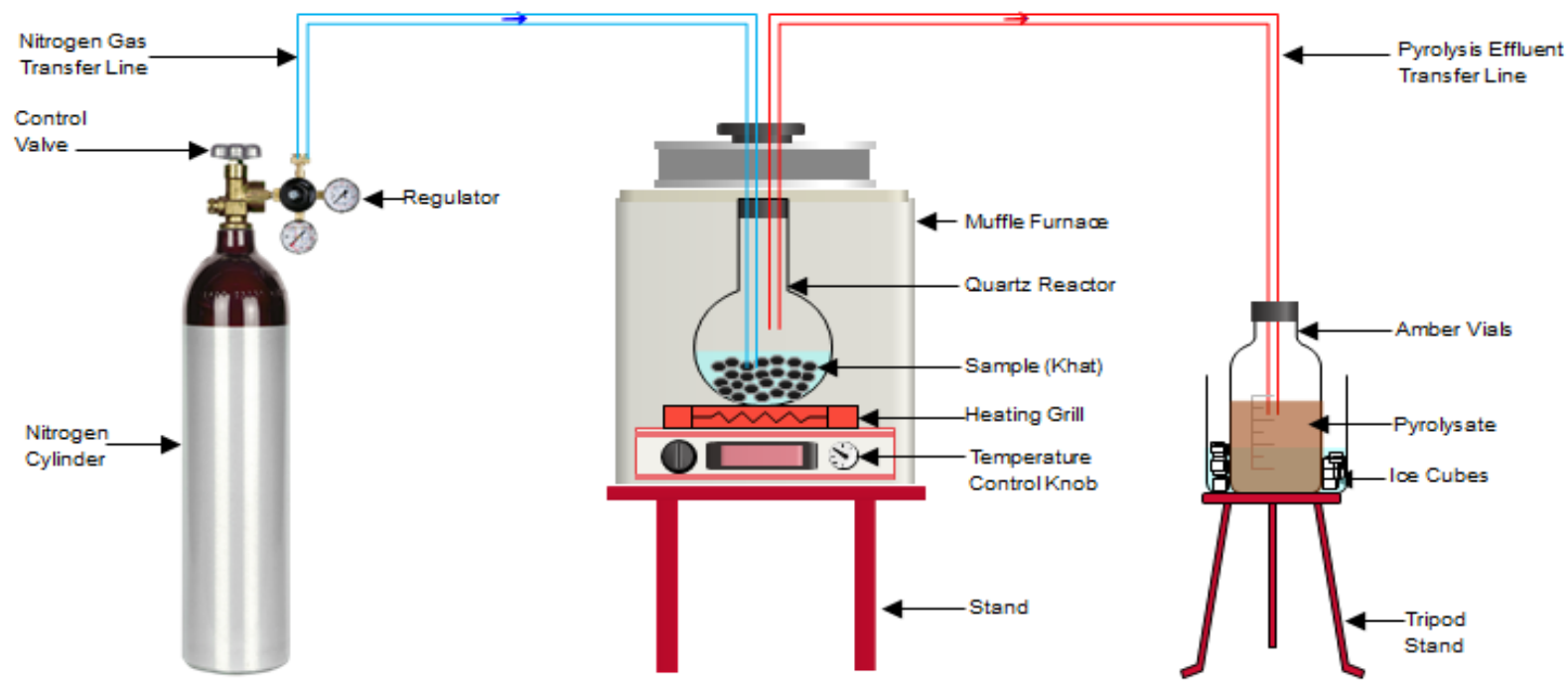

Fig 4: Reactor assembly

2.4 Sample introduction into the reactor

$30 \pm 0.2 \mathrm{mg}$ of the sample was weighed and placed inside the quartz tube and held in place by quartz reactor. The temperature console was set to $200{ }^{\circ} \mathrm{C}$ and adjusted in increment intervals of $50{ }^{\circ} \mathrm{C}$ up to a temperature of $700{ }^{\circ} \mathrm{C}$ on the fractional pyrolysis mode. The effluent flowing from the reactor was then transmitted through a deactivated silica coated transfer line that was kept at a constant temperature of
$270{ }^{\circ} \mathrm{C}$ to prevent condensation along the transfer line into $2 \mathrm{~mL}$ methanol in crimp top vials as a pyrolysate. The pyrolysate was analyzed using a Gas Chromatography hyphenated to a Mass selective detector (MSD). The char yield at every temperature was calculated using the method of difference as described by Soi et al. (2015), [24] The char obtained at selected temperatures were packaged in crimp top vials for elemental analysis.

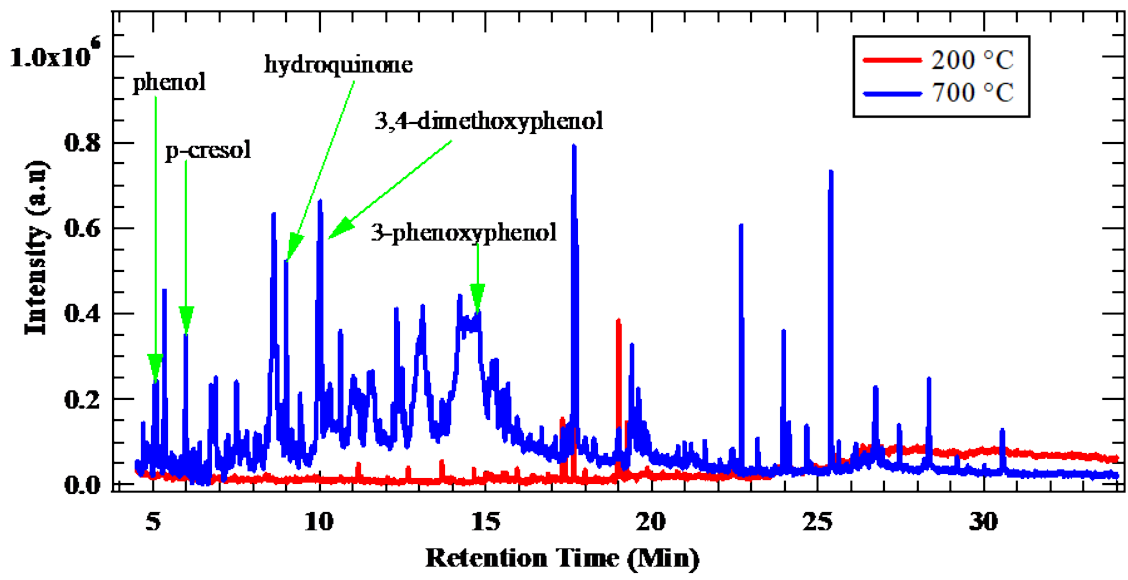

Fig 5: Overlay GC-MS chromatogram for phenolic compounds released from khat pyrolysis

\subsection{Characterization of phenolic compounds from thermal} effluent of khat

An Agilent 6890N gas chromatograph instrument equipped with a $5973 \mathrm{~N}$ mass selective detector (MSD) with an ion source electron impact (EI) of $70 \mathrm{eV}$ was used to analyse the pyrolysate. A DB5-MS column $(30 \mathrm{~m} \times 0.25 \mathrm{~mm} \times 0.25 \mu \mathrm{m})$ was used to analyse molecules present in khat pyrolysate. A $1 \mu \mathrm{L}$ of the liquid sample was injected into the GC column whose injection port temperature was set at 200 ${ }^{\circ} \mathrm{C}$. The temperature programming was adjusted so as to heat at a rate of $25^{\circ} \mathrm{C} / \mathrm{min}$ at $50{ }^{\circ} \mathrm{C}$ for 10 minutes and hold for 2 minutes at $250{ }^{\circ} \mathrm{C}$ and followed by a heating rate of $10^{\circ} \mathrm{C} / \mathrm{min}$ and holding for 10 minutes at $300{ }^{\circ} \mathrm{C}$. The identified phenolic compounds were comprehensively checked run through NIST identification software and confirmed using ChemStation Agilent software in order to guarantee accurate reporting of the reaction products. To ensure that the correct compound was positively identified the retention times of pure compounds (standards) were determined and matched with those of the analytes. 


\section{Results and discussion}

\subsection{Phenolic compounds released from khat pyrolysis}

During the thermal degradation of dried khat leaves under conditions that simulate cigarette smoking, a range of phenolic pyrolysis products were released at various pyrolysis temperatures. It can be observed from Fig. 5 that most phenolic products were evolved a temperatures ranging between 300 and $500{ }^{\circ} \mathrm{C}$. Evidently from the obtained results, the pyrolysis of khat generates a series of phenolic compounds such as p-cresol, catechol, hydroquinone and other substituted methoxy phenols including 3-methoxy phenol. The release of the pyrolysis phenolic products showed a variation in concentrations at various temperatures with peak concentrations being achieved at temperatures ranging between $400{ }^{\circ} \mathrm{C}-550{ }^{\circ} \mathrm{C}$ as illustrated in Fig. 5. Notably, at high temperatures of about $700{ }^{\circ} \mathrm{C}$ more phenolic compounds were generated compared to low temperatures of around $200^{\circ} \mathrm{C}$.

Phenolic compounds attained maximum release temperature at about $450{ }^{\circ} \mathrm{C}$ and $550{ }^{\circ} \mathrm{C}$ at which $p$-cresol, phenol and its corresponding substituted molecular products such as 3-phenoxy phenol, 2, 6dimethoxy-4-allylphenol and 3,4-dimethoxyphenol registered the highest yeields. Hydroquinone peaked at about $500{ }^{\circ} \mathrm{C}$ with a yield of $11.12 \%$ and a total yield of $21.32 \%$ in the entire temperature range. This represented nearly $40 \%$ of the total phenol content reported in this study. The total yield of phenol and p-cresol in the entire pyrolysis temperature range were 5.67 and $2.54 \%$, respectively. This suggests that the major phenolic component in khat pyrolysis is hydroquinone, and is perhaps the most potent chemical in khat smoking. The phenolic compounds detected in low yields (Fig. 6b) included 4-methoxybenzene-1,2-diol. On the other hand, methoxy phenol compounds were reported in fairly higher yields from of 400 ${ }^{\circ} \mathrm{C}$, attained a maximum evolution at $500{ }^{\circ} \mathrm{C}$ before decreasing sharply at $650{ }^{\circ} \mathrm{C}$. Compounds such as methoxy phenyl acetic acid and 1, 4dimethoxy-2-methylbenzene were produced at low concentration throughout the pyrolysis temperature range while 3-methoxy acetophenone depicted the highest concentration of $8.82 \%$ as illustrated in Fig. 6b. 3,4-dimethoxyphenol gave a yield of $\sim 6 \%$ in the entire pyrolysis temperature range while 3-phenoxyphenol was $3.6 \%$ in the whole temeprature range.
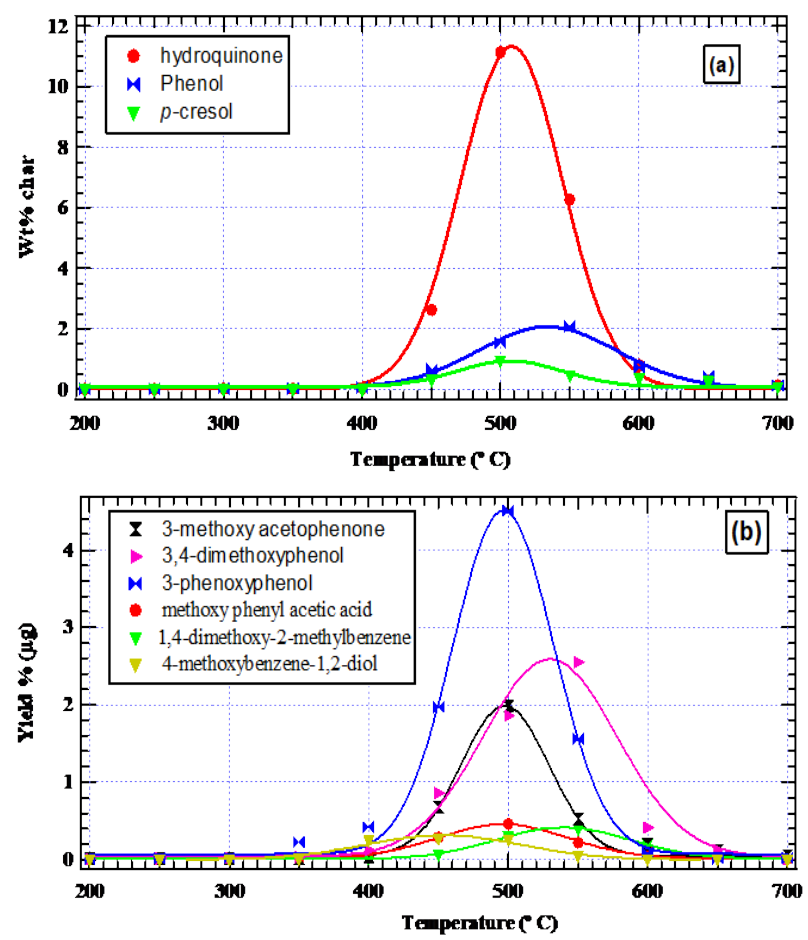

Fig 6 Phenolic (a) and (b) methoxy phenol compounds distribution from khat biomass pyrolysis

It is important to note from the khat pyrolysis experiments, that all reported phenolic compounds had their concentration profiles increasing with increase in temperature upto approximately between
400-600 ${ }^{\circ} \mathrm{C}$ before decreasing between 650 and $700{ }^{\circ} \mathrm{C}$ where the oxygenated components are completely decomposed. This can be illustrated in the percentage mass loss profiles at the pyrolysis temperature range shown in Fig. 7. The mass loss between $200-350^{\circ} \mathrm{C}$ was approximately $12 \%$ whereas between $350-550{ }^{\circ} \mathrm{C}$, the mass loss was $\sim 65 \%$. This coincides with the region where there is a high evolution of pyrolysis products and is consistent with literature studies. The next regime begins from $550-700{ }^{\circ} \mathrm{C}$ during which a mass loss of $\sim 11 \%$ is observed. At about $650{ }^{\circ} \mathrm{C}$, the pyrolysis material is largely carbon. Evidently, khat pyrolysis is accompanied by loss of weight as the temperature increases. The greatest loss of weight was achieved at a temperatures of about $500^{\circ} \mathrm{C}$. The main reason for such pyrolysis behaviour is mainly due to the release of most pyrolysis products at this temperature.

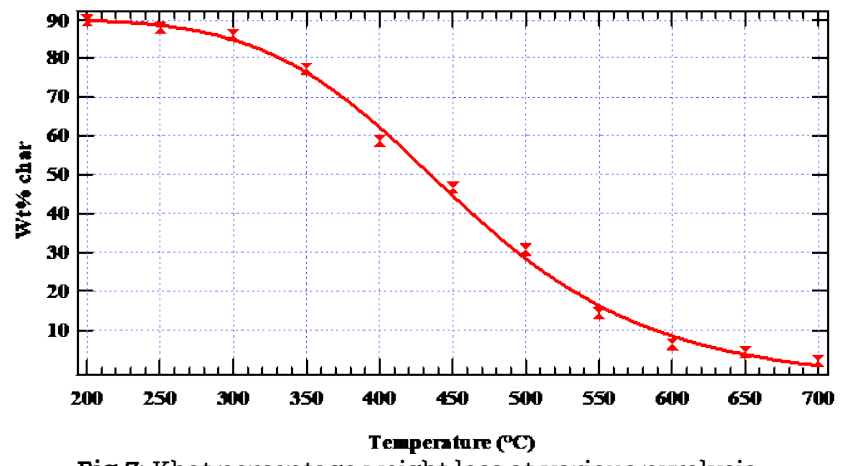

Fig 7: Khat percentage weight loss at various pyrolysis temperatures

\subsection{Elemental analysis}

Elemental analysis of char obtained from the thermal degradation of khat indicated a variation of the percentage composition of $\mathrm{O}, \mathrm{C}, \mathrm{N}, \mathrm{H}$ and $\mathrm{S}$ as shown in Table 1. Carbon content in char from khat pyrolysis at $400{ }^{\circ} \mathrm{C}$ was found to be $37.08 \%$ while that of oxygen was significantly high (43.73\%) which can be attributed to the presence of oxygenated organic components such as esters, phenols alkanoic acids and other oxygenated molecular compounds such as aldehydes and ketones. Hydrogen, nitrogen and sulphur were also reported in slightly lower concentrations of as displayed in Table 1.

Table 1: Elemental composition of khat thermal char at $400^{\circ} \mathrm{C}$

\begin{tabular}{ccc}
\hline & Element & Composition (\%) \\
\hline & $\mathrm{C}$ & 37.08 \\
$\mathrm{~N}$ & 1.47 \\
$\mathrm{H}$ & 5.52 \\
& $\mathrm{O}$ & 43.73 \\
& $\mathrm{~S}$ & 0.14 \\
Total & & \\
& & $\mathbf{8 7 . 9 4 \%}$
\end{tabular}

These elements especially nitrogen and sulphur are well known to be constituents of toxic compounds such as the nitrogen containing hydrocarbons (cathinone, pyridine, and pyrrole) which are notorious environmental contaminants and are capable of causing serious health problems.

\subsection{Health implications of phenolic compounds}

Phenols from khat pyrolysis, especially substituted phenols are known to be highly toxic given that they possess electron donating substituents, mainly the methyl groups. Moreover, the conjugation between the oxygen atom electron pair with the aromatic system results in increased polarity because of the transfer of negative charge from the oxygen atom to the aromatic ring and charge delocalization phenolic compounds are considered highly reactive against biological systems once they gain entry into the human body system. For instance, during thermal degradation, hydroquinone breaks down into environmentally active radicals as illustrated in scheme 1. 
<smiles></smiles>

Scheme 1: Hydroquinone thermal degradation to hydroxyquinoxy free radicals

Moreover, hydroquinone becomes polarized and consequently gains acidic properties by forming hydroxyphenolate ion whose negative charge distribution around the molecule can be demonstrated by resonance hybrids as shown in scheme 2, vide infra. These characteristic features of hydroquinone with respect to the presence of substituent groups attached to the aromatic ring depending on its ability to withdraw or donate electrons [1]. It can be observed from scheme 2 that the resonance stabilization for phenolic compounds is possibly a result of separation of charge which leads to compound stabilization. Therefore, since the resonance stabilization of hydroxyphenolate ion is greater than stabilization of hydroquinone, it is more likely that it is highly polar than its parent molecule, hydroquinone. Remarkably, similar reaction patterns are likely to be noted in many other phenolic compounds such as phenol.<smiles>CC(C)(C)Oc1ccc(O)cc1OCCOc1ccc(O)cc1</smiles>

Scheme 2: Resonance stabilized structures for hydroquinone

The low polar nature of hydroquinone can be associated with its ability to form hydrogen bonds that strengthen the structural symmetry of the hydroquinone molecule. A hydroquinone molecule produces a strong structure which is highly hydrophobic and therefore most likely insoluble in human biological systems such as fatty tissues. This hydrophobic behaviour is a precursor for oxidative stress. On the hand, its conversion to hydroxyphenolate ion makes it more toxic when bound to polar biological structures such as DNA and amino acids.

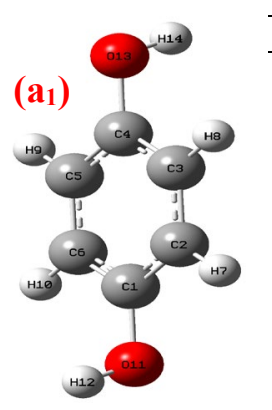

\begin{tabular}{ll}
\hline Bond length & Bond angle \\
\hline $\mathrm{C}-\mathrm{O}=1.43000$ & $\mathrm{C}-\mathrm{C}-\mathrm{C}=120.00000$ \\
$\mathrm{C}-\mathrm{C}=1.40140$ & $\mathrm{C}-\mathrm{C}-\mathrm{O}=120.00000$ \\
$\mathrm{C}-\mathrm{H}=1.07000$ & $\mathrm{H}-\mathrm{C}-\mathrm{C}=120.00000$ \\
$\mathrm{H}-\mathrm{O}=0.96000$ & $\mathrm{H}-\mathrm{O}-\mathrm{C}=109.47122$
\end{tabular}

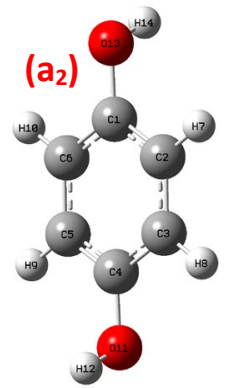

\begin{tabular}{ll}
\hline Bond length & Bond angle \\
\hline $\mathrm{C}-\mathrm{O}=1.39040$ & $\mathrm{C}-\mathrm{C}-\mathrm{C}=119.95711$ \\
$\mathrm{C}-\mathrm{C}=1.39346$ & $\mathrm{C}-\mathrm{C}-\mathrm{O}=119.90918$ \\
$\mathrm{C}-\mathrm{H}=1.08386$ & $\mathrm{H}-\mathrm{C} \mathrm{C}=120.82859$ \\
$\mathrm{H}-\mathrm{O}=0.96265$ & $\mathrm{H}-\mathrm{O}-\mathrm{C}=109.76314$
\end{tabular}

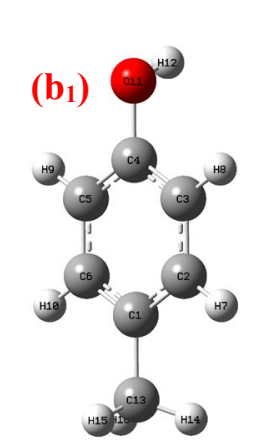

$\begin{array}{ll}\mathrm{C}-\mathrm{O}=1.4300 & \mathrm{C}-\mathrm{C}-\mathrm{C}=120.00000 \\ \mathrm{C}-\mathrm{C}=1.4014 & \mathrm{C}-\mathrm{C}-\mathrm{O}=120.00000 \\ \mathrm{C}-\mathrm{H}=1.0700 & \mathrm{H}-\mathrm{C}-\mathrm{C}=120.00000 \\ \mathrm{H}-\mathrm{O}=0.9600 & \mathrm{H}-\mathrm{O}-\mathrm{C}=109.47122\end{array}$

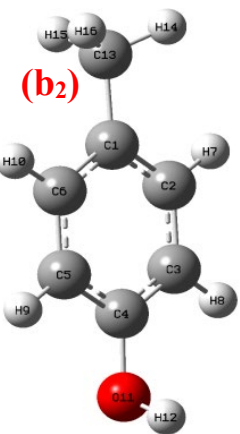

$\mathrm{C}-\mathrm{O}=1.39272$
$\mathrm{C}-\mathrm{C}=1.39598$
$\mathrm{C}-\mathrm{H}=1.08757$
$\mathrm{H}-\mathrm{O}=0.96615$

C-C-C $=119.73351$

$C-C-O=119.98037$ $\mathrm{H}-\mathrm{C}-\mathrm{C}=120.00000$

$\mathrm{C}-\mathrm{O}=1.43000$

C-C $-\mathrm{C}=120.00000$ C-C $-\mathrm{O}=120.00000$

$\mathrm{C}-\mathrm{C}=1.40140$ $\mathrm{H}-\mathrm{C}-\mathrm{C}=120.00000$
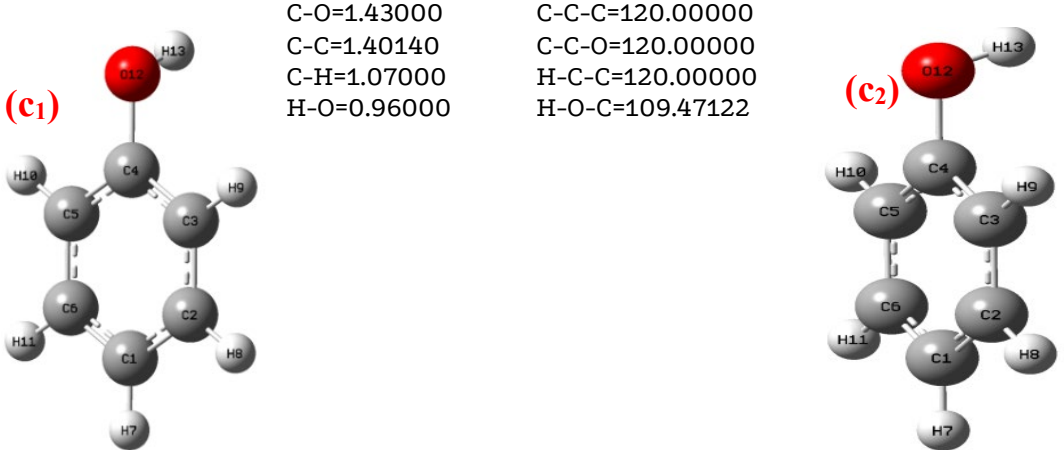

$\mathrm{C}-\mathrm{O}=1.39179$

$C-C-C=120.31110$

$\mathrm{C}-\mathrm{C}=1.39725$

$\mathrm{C}-\mathrm{C}-\mathrm{O}=119.71900$

$\mathrm{H}-\mathrm{O}-\mathrm{C}=109.47122$

$\mathrm{C}-\mathrm{H}=1.08570$

$\mathrm{H}-\mathrm{C}-\mathrm{C}=121.24454$

$\mathrm{H}-\mathrm{O}=0.96624 \quad \mathrm{H}-\mathrm{O}-\mathrm{C}=109.95496$

Fig 8: (1) input and (2) optimized geometries and geometric parameters for (a) hydroquinone (b) p-cresol (c) phenol

Besides, the detection of $p$-cresol in khat smoke is a health concern. This is because $p$-cresol has been reported to be highly toxic by various scientific studies especially when their main entry route into human body system is via the oral, subcutaneous, and intravenous or intrapertoneal where it is more likely to cause tissue corrosion along the involved body parts thus resulting to cardiovascular diseases and consequently established as a protein bound uremic toxin $[25,26]$. 
During thermal degradation reactions, $p$-cresol compound converts into radicals which are highly reactive to bio-systems and are likely to initiate more devastating reactions with body tissues. Scheme 3 demonstrates the formation of radicals from $\mathrm{p}$-cresol as a result of thermal degradation.<smiles>Cc1ccc(O)c(I)c1</smiles>

Scheme 3: $p$-cresol thermal degradation to radicals

\subsection{Molecular modelling of phenolic compounds}

The energies, molecular structures and vibrational frequencies of selected phenolic compounds generated from khat pyrolysis were predicted using Gaussian 09 computational package. The optimized geometries of the compounds are preseneted in Fig 8. The energies, thermodynamic properties, geometry optimizations and frequencies were calculated using DFT quantum level of theory using 6-311G++ basis set under the Becke's three parameter Lee-Yang-Parr (B3LYP) hybrid function as described elsehere [27]. In order to calculate the associated energy change in the formation of free radicals from phenols, equation 2 was employed [26].

$\Delta_{r} H^{\circ}=\sum\left(\varepsilon_{0}-H_{\text {corr }}\right)_{\text {products }}-\sum\left(\varepsilon_{0}-H_{\text {corr }}\right)_{\text {Reactants }} \quad$ Equation 2 where, $\Delta_{r} H^{\circ}$ is change in enthalpy of the reaction, $H_{\text {corr }}$ is correction to the thermal enthalpy and $\varepsilon_{0}$ is the sum of electronic and thermal enthalpies.

The estimated energy changes for radicals formed from major phenols as a function of pyrlysis temperature is presented in Fig 9. It can be observed from Fig. 9 that during the thermal degradation of phenols, the endothermicity of the reaction involving the formation of radicals increases with increase in whole temperature range. Remarkably, phenol transformation into its corresponding free radical (phenoxy) was accompanied by the greatest energy change, followed by the formation of hydroquinoxyl and methylphenoxy free radicals, respectively.

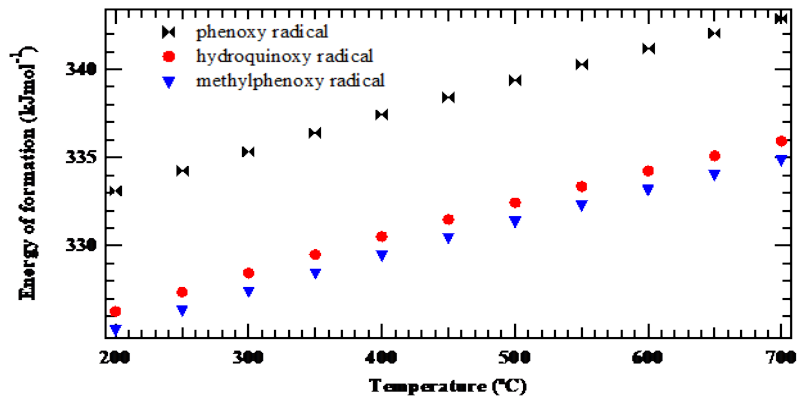

Fig 9: Energy change plots for the formation of radicals from phenolic compounds

\subsection{Molecular geometries and their corresponding potential energy surfaces}

The molecular structures for selected compounds can be defined by geometric parameters that include bond lengths and bond angles that determine their inherent bond strengths. Fig 8 gives a summary of the geometry parameters for hydroquinone, p-cresol and phenol Comparisons are made between the input and the optimized structures. It was noted that $\mathrm{p}$-cresol readily undergoes chemical reactions that subsequently lead to the formation of free radicals. Some of these radicals form part of the smoked effluent from khat which gains entry into the human biosystem. Once inside the human body, they are likely to manifest deleterious biological action such as cardiac arrest and oxidative stress and can exhibit aromatism that may yield environmentally persistent free radicals.

On the other hand, optimization steps taken in attaining the most stable conformation at its minimum energy reveals more information regarding molecular stability. It shows the number of steps taken by a molecule in order to attain its most stable molecular structure and the net inter-atomic forces that exist within the molecule atoms [5]. The most unstable structures have the highest optimization steps. Accordingly, phenol and hydroquinone had 5 optimization step in order to reach their most stable conformations at -307.55 and -382.79 hartrees, respectively while $p$-cresol exhibited 7 optimization step at -346.24 hartrees. This information confirms the assertion that $p$ cresol is more reactive as compared to phenols explored in this study.

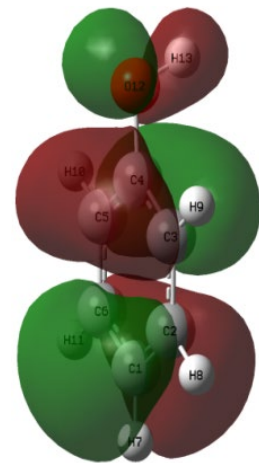

$\left(a_{1}\right)$

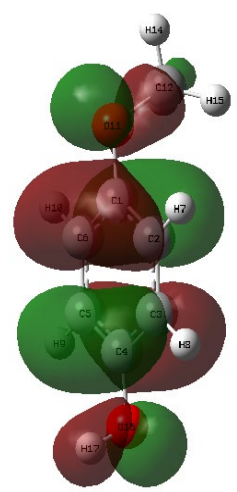

$\left(b_{1}\right)$

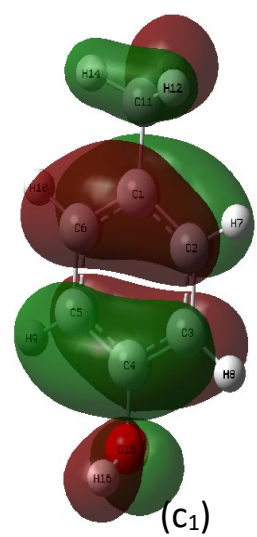

(c)

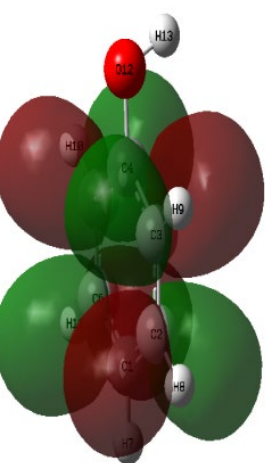

$\left(a_{2}\right)$

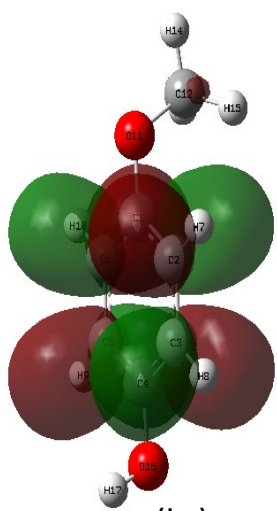

$\left(b_{2}\right)$

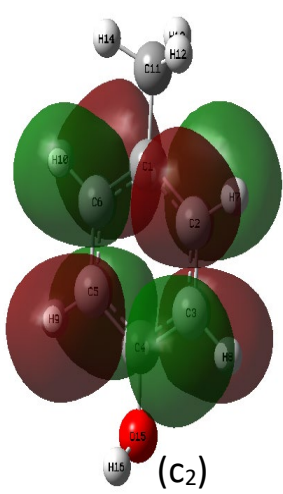

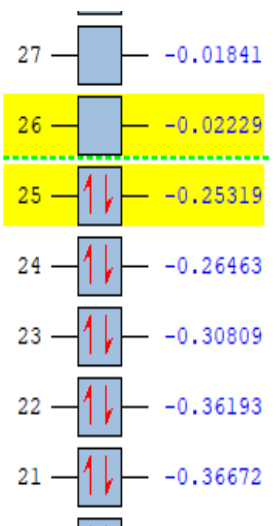

$35-\square-0.01754$

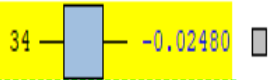

$33-11-0.24429$

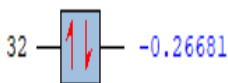

$31-11-0.28287$

$30-11--0.30912$

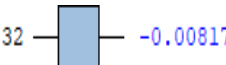

$31-\square-0.01572$

$30-\quad-0.02067$

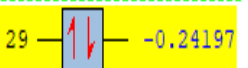

$28-11-0.26127$

$27-11-0.30470$

$26-11-0.35011$

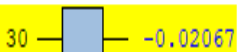

Fig 10: HOMO (1) LUMO (2) for hydroquinone (a) phenol (b) and p-cresol (c) and their energies 


\subsection{Molecular orbitals and Electronic properties}

The highest occupied molecular orbital (HOMO)-lowest unoccupied molecular orbital (LUMO) energy gap can also be used to predict the strength and stability of molecules and consequently the reactivity of molecules [5, 28]. The HOMO-LUMO energy profiles for hydroquinone, phenol and p-cresol is as presented in Fig 10. Evidently, it can be deduced from the energy profiles obtained that the HOMO for hydroquinone, $p$-cresol and phenol is $-0.24708,-0.24197$ and -0.25319 $\mathrm{eV}$, respectively at an iso value of 0.02 and singlet spins under alpha occupancy. Similarly, the LUMO were at $-0.02687,-0.02067$ and $0.02480 \mathrm{eV}$, respectively. This gives rise to HOMO-LUMO band gap energy of $-0.17838,-0.22021$ and $-0.02229 \mathrm{eV}$, correspondingly

Phenol exhibited the smallest band gap energy while $p$-cresol exhibited the largest band gap energy suggesting that $p$-cresol is the most unstable phenolic compound and hence more reactive. This is in agreement with our earlier suggestion that $p$-cresol is more toxic given that it has a high affinity to human body cells and has the potential to induce harmful cell reactions that probably can lead to carcinogenesis and mutagenesis. Because these phenolic compounds have a high degree of unsaturation, hydroquinone and phenol are considered harmful because once they gain entry into the human biological system, cyclic transition reactions occur at the region of double bonds "diene" where there exists conjugated double pi-bonds with the single pi-bond sites "dienophile" comprising of conjugated $\pi$ electron system within unsaturated biological molecules that include fats and lipids [5].

These active sites can be highlighted using electron density and contour maps as shown in Fig 11. The electrostatic potential values are usually assigned coded colors - green color indicative of sites with high positive values where the excitation states are greatest while red color indicates points or regions where electrophilic attack is likely to occur.

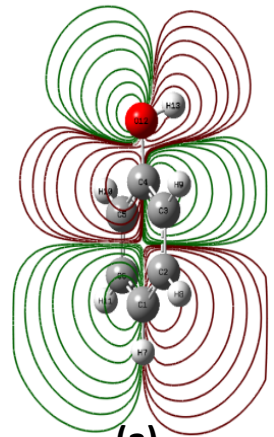

(a)

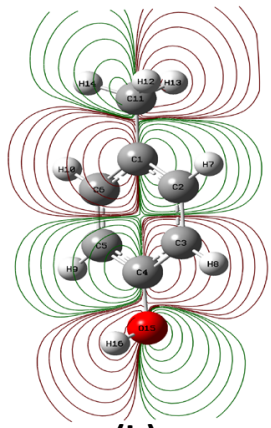

(b)

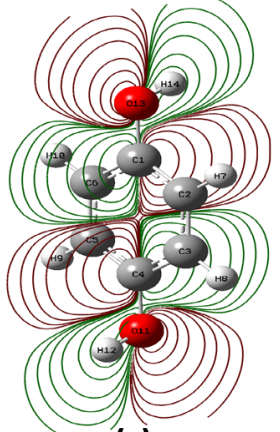

(c)
Fig 11: contour maps for (a) phenol (b) p-cresol (c) hydroquinone

\section{Conclusion}

This work has demonstrated that the thermal degradation of khat biomass leads to the formation of a number of toxic phenolic compounds; phenol, $p$-cresol, catechol, hydroquinone and other substituted methoxy phenols including 3-phenoxy phenol, and 3,4dimethoxyphenol. The concentrations of most phenolic compounds peaked between $400{ }^{\circ} \mathrm{C}-550{ }^{\circ} \mathrm{C}$. Hydroquinone represented nearly $40 \%$ of phenol content reported in this study. This suggests that the major phenolic component in khat pyrolysis is hydroquinone, and is perhaps the most potent chemical in khat smoking. Other phenolic compounds of concern include phenol and $p$-cresol. The evolution of phenolic compounds during the thermolysis of khat is a serious concern because of their associated toxicological impacts especially among khat smokers. Simulated data has confirmed that $p$-cresol is the most reactive phenolic component. It is evident that some of the toxic phenolic compounds such as $p$-cresol are predominantly released from khat pyrolysis and are likely to cause serious biological effects in humans. Elemental analysis data of thermal char at $400{ }^{\circ} \mathrm{C}$ showed that oxygenated compounds dominated at approximately $43 \%$. This is consistent with evolution of oxygenated molecular compounds such as phenols at this temeperature as reported in literature. These findings should assist government authorities and medical practitioners to design policies aimed at discouraging the khat smoking community, and prevent the abuse of khat as a drug.

\section{Authors' contributions}

Micah O. Omare: Formal analysis, and Writing original draft. Joshua K. Kibet: Conceptualization, Methodology, Formal analysis, Writing \& Editing, Validation \& Supervision. Jackson K. Cherutoi: Project administration, Resources, Review \& Editing. Fredrick O. Kengara: Writing \& Editing, Validation \& Supervision.

\section{Acknowledgements}

The authors are thankful to the Africa Center of Excellence II in Phytochemicals, Textiles and Renewable Energy (ACE II PTRE)-Moi for facilitating the success of this study.

\section{Funding}

The authors are grateful to the Africa Center of Excellence II in Phytochemicals, Textiles and Renewable Energy (ACE II PTRE) for funding this research.

\section{Declaration of Conflict of Interests}

The authors declare that there is no conflict of interest. They have no known competing financial interests or personal relationships that could have appeared to influence the work reported in this paper.

\section{References}

[1.] Sobiesiak M. Chemical Structure of Phenols and Its Consequence for Sorption Processes. 2017.

[2.] Kibet J, Khachatryan L, Dellinger B. Phenols from pyrolysis and co-pyrolysis of tobacco biomass components. Chemosphere. 2015; 138:259-65.

[3.] Saha P, Talukdar AD, Nath R, Sarker SD, Nahar L, Sahu J, et al. Role of Natural Phenolics in Hepatoprotection: A Mechanistic Review and Analysis of Regulatory Network of Associated Genes. Front Pharmacol. 2019; 10:509-. doi: 10.3389/fphar.2019.00509. PubMed PMID: 31178720.

[4.] Carrier N, Klantschnig G. Quasilegality: khat, cannabis and Africa's drug laws. Third World Quarterly. 2018;39(2):350-65. doi: 10.1080/01436597.2017.1368383.

[5.] Omare MO, Kibet JK, Cherutoi JK, Kengara FO. Contemporary Trends in the Use of Khat for Recreational Purposes and Its Possible Health Implications. OALibJ. 2020;7(12):1-22. doi: 10.4236/oalib.1106985.

[6.] Corkery JM. Khat-chewing it over: continuing cultural cement', cardiac challenge or catalyst for change? Susannah Davies AJ, David Holt, editor: Royal Society of Chemistry; 2016. 165-207.

[7.] Eligh J. The Evolution of Illicit Drug Markets and Drug Policy in Africa. ENACT Report. Global Initiative Against Transnational Organised Crime; 2019.

[8.] Orlien SMS, Sandven I, Berhe NB, Ismael NY, Ahmed TA, SteneJohansen $\mathrm{K}$, et al. Khat chewing increases the risk for developing chronic liver disease: A hospital-based case-control study. Hepatology. 2018;68(1):248-57. doi: 10.1002/hep.29809.

[9.] Laura C, Scot T, Ryan K, Sophie S, Nitara O, Kristina A. what are the effects of khat? Sunrise House; American Addiction Centers Treatment Facility. 2019.

[10.] Mandi G. Miraa a Gold Platter in Taita Taveta County. Kwaela News Network. 2019.

[11.] CDC. Current cigarette smoking among adults-United States, 2011. MMWR Morb Mortal Wkly Rep. 2012;61(44):889.

[12.] Capistrano SJ, van Reyk D, Chen H, Oliver BG. Evidence of Biomass Smoke Exposure as a Causative Factor for the 
Development of COPD. Toxics. 2017;5(4):36. doi: 10.3390/toxics5040036. PubMed PMID: 29194400.

[13.] Chen W, Brehm JM, Manichaikul A, Cho MH, Boutaoui N, Yan Q, et al. A genome-wide association study of chronic obstructive pulmonary disease in Hispanics. Ann Am Thorac Soc 2015;12(3):340-8. Epub 2015/01/15. doi: 10.1513/AnnalsATS.201408-3800C. PubMed PMID: 25584925; PubMed Central PMCID: PMCPmc4418314.

[14.] Lovering AT, Elliott JE, Laurie SS, Beasley KM, Gust CE, Mangum TS, et al. Ventilatory and sensory responses in adult survivors of preterm birth and bronchopulmonary dysplasia with reduced exercise capacity. Ann Am Thorac Soc. 2014;11(10):1528-37. Epub 2014/11/08. doi: 10.1513/AnnalsATS.201312-4660C. PubMed PMID: 25380058.

[15.] Salvi S, Barnes PJ. Is exposure to biomass smoke the biggest risk factor for COPD globally? Chest. 2010;138(1):3-6. Epub 2010/07/08. doi: 10.1378/chest.10-0645. PubMed PMID: 20605806.

[16.] Silva R, Oyarzún M, Olloquequi J. Pathogenic mechanisms in chronic obstructive pulmonary disease due to biomass smoke exposure. Archivos de bronconeumologia. 2015;51(6):285-92. Epub 2015/01/24. doi: 10.1016/j.arbres.2014.10.005. PubMed PMID: 25614376.

[17.] LoPachin RM, Gavin T. Molecular mechanisms of aldehyde toxicity: a chemical perspective. Chemical research in toxicology. 2014;27(7):1081-91.

[18.] Lin H, Ye Q, Deng C, Zhang X. Field analysis of acetaldehyde in mainstream tobacco smoke using solid-phase microextraction and a portable gas chromatograph. Journal of Chromatography A. 2008;1198:34-7.

[19.] Luo K, Stepanov I, Hecht SS. Chemical biomarkers of exposure and early damage from potentially carcinogenic airborne pollutants. Annals of Cancer Epidemiology; Vol 3 (September 2019): Annals of Cancer Epidemiology. 2019.

[20.] World Health Organization. WHO study group on tobacco product regulation: report on the scientific basis of tobacco product regulation: seventh report of a WHO study group. 2019.

[21.] Pan B, Li H, Lang D, Xing B. Environmentally persistent free radicals: occurrence, formation mechanisms and implications. Environmental Pollution. 2019;248:320-31.

[22.] Lam Y-h, Abramov Y, Ananthula RS, Elward JM, Hilden LR, Nilsson Lill SO, et al. Applications of Quantum Chemistry in Pharmaceutical Process Development: Current State and Opportunities. Organic Process Research \& Development. 2020;24(8):1496-507.

[23.] Maheshwari S, Li Y, Agrawal N, Janik MJ. Density functional theory models for electrocatalytic reactions. Advances in Catalysis. 63: Elsevier; 2018. p. 117-67.

[24.] Soi C, Muriithi N, Keriko J, Kurgat C, Kibet J. The ash content from the thermal degradation of selected biomass waste from Githurai market, NairobiI, Keya. Int Multidiscip Res J. 2015;1(4):194-6.

[25.] Langman LJ, Jannetto PJ. Toxicology and the clinical laboratory. Contemporary Practice in Clinical Chemistry: Elsevier; 2020. p. 913-47.

[26.] Mosonik BC, Ngari SM, Kibet JK. Molecular Modelling of Selected Combustion By-Products from the Thermal Degradation of Croton megalocarpus Biodiesel. oalibj. 2019;6(10):1. doi: 10.4236/oalib.1105840.

[27.] Smith MW, Dallmeyer I, Johnson TJ, Brauer CS, McEwen J-S, Espinal JF, et al. Structural analysis of char by Raman spectroscopy: Improving band assignments through computational calculations from first principles. Carbon. 2016;100:678-92.

[28.] Bartocci E, Lió P. Computational Modeling, Formal Analysis, and Tools for Systems Biology. PLOS Computational Biology. 2016;12(1):e1004591. doi: 10.1371/journal.pcbi.1004591.

\section{How to Cite This Article}

Omare, M.O, Kibet, J.K, Cherutoi, J.K, and Kengara, F.O, Phenolic reaction products from the thermal degradation of Catha edulis, Journal of Nature, Science \& Technology, 3(2021), 17-24. https://doi.org/10.36937/janset.2021.003.004 